\title{
SOBRE A (SUPOSTA) DEDUÇÃO DA III SECÇÃO DA FUNDAMENTAÇÃ̃O
}

\author{
Flávia Carvalho Chagas \\ Universidade Federal de Pelotas
}

\begin{abstract}
This paper intend to investigate the nature of the central argument of GMS III and show why this can not solve the problem that it addresses, namely, prove the objective validity of the supreme principle of morality to human rational beings.
\end{abstract}

KEYWORDS: GMS III, objective validity, categorical imperative.

RESUMO: Este artigo pretende investigar a natureza do argumento central da GMS III e mostrar porque este não consegue resolver o problema a que ele se dirige, a saber, provar a validade objetiva do princípio supremo da moralidade para seres racionais humanos.

PALAVRAS-CHAVE: GMS III, validade objetiva, imperativo categórico.

Já a partir do título de uma das principais obras em que Kant se dedica ao problema da justificação do seu princípio moral, a saber, a Fundamentação da Metafísica dos Costumes ${ }^{1}$, podemos supor encontrar ali o sucesso de tal empreendimento.

Todavia, parece-nos que não há uma resposta clara e consensual entre os intérpretes da ética kantiana sobre se há, de fato, uma dedução do imperativo categórico na III Seção da GMS. Com efeito, na medida em que lemos no Prefácio desta obra que o seu objetivo consiste na "busca e fixação do princípio supremo da moralidade”, o leitor espera encontrar tal fundamentação.

\footnotetext{
${ }^{1}$ Adotarei as seguintes siglas das obras de Kant: Fundamentação da Metafísica dos Costumes (GMS), Crítica da Razão Prática (KpV), Crítica da Razão Pura (KrV).
} 
Além disso, um outro ponto que parece ainda pouco explorado, e que constitui um dos problemas cruciais na interpretação do projeto kantiano da fundamentação de um princípio moral universalmente válido, diz respeito a como nós podemos entender a ligação entre os dois escritos principais de Kant sobre o problema da prova da validade e da necessidade da consciência da lei moral para seres racionais humanos, a saber, a $G M S$ e a $K p V$.

Assim, um dos objetivos deste texto consiste na determinação da ligação (ou não) entre as teses da III Seção da $G M S$ e da $K p V$. Embora seja afirmado no Prefácio da segunda Crítica que esta obra "pressupõe a Fundamentação da metafísica dos costumes, mas só na medida em que esta chega a conhecer provisoriamente o princípio do dever e indica e justifica uma fórmula determinada deste" ( $K p V$, A 14$)$, não é claro se há ou não uma continuidade entre estes dois textos quanto ao problema da prova da necessidade prática de se submeter ao imperativo categórico. Com isso, pretendemos reconstruir os argumentos da III Seção da GMS para, então, investigar se e como é possível estabelecer uma ligação deste texto com a $K p V$.

O ponto de partida da III Seção da GMS consiste na explicitação daquilo que, segundo Kant, vem a ser a chave para a explicação do conceito de autonomia da vontade, a saber, o conceito de liberdade. Ali, o conceito de vontade é definido como uma "espécie de causalidade" própria do ser racional sendo que o conceito de liberdade consiste na propriedade desta faculdade prática, quer dizer, a liberdade indica o modo de atuação de uma vontade que não é determinada exclusivamente por motivações empíricas ${ }^{2}$.

Entretanto, como Kant afirma, a definição da liberdade exposta no início desta Seção é insuficiente para determinar o conteúdo desta idéia tendo em vista que ela é concebida apenas negativamente como a capacidade da vontade de agir "independentemente de causas estranhas que a determinem” (GMS, Ak 446). Assim, a explicação da derivação da idéia positiva da liberdade, entendida enquanto autonomia consiste em afirmar que:

Como o conceito de uma causalidade traz consigo o de leis segundo as quais, por meio de uma coisa a que chamamos

\footnotetext{
2 Neste parágrafo de abertura desta Seção, Kant contrapõe os conceitos da vontade (entendida como um tipo de causalidade de seres racionais) e da causalidade dos seres irracionais; essa, por sua vez, vinculada a uma outra "propriedade" enquanto modo de atuação, que é a da necessidade natural.
} 
causa, tem de ser posta outra coisa que se chama efeito, assim a liberdade, se bem que não seja uma propriedade da vontade segundo leis naturais, não é por isso desprovida de lei, mas tem antes de ser uma causalidade segundo leis imutáveis, ainda que de uma espécie particular (...). A necessidade natural era uma heteronomia das causas eficientes; pois todo o efeito era só possível segundo a lei de que alguma outra coisa determinasse à causalidade a causa eficiente; que outra coisa pode ser, pois, a liberdade da vontade senão autonomia, i. é a propriedade da vontade de ser lei para si mesma? (GMS, Ak 446/ 447).

Com esta derivação do conceito positivo da liberdade a partir do negativo, Kant conclui o argumento que estabelece a relação que há entre liberdade e moralidade, ou seja, a partir desta análise do sentido negativo daquela idéia é possível mostrar a implicação mútua entre as idéias da liberdade e da moralidade ${ }^{3}$.

Esta mútua implicação significa então, que a vontade, na medida em que expressa um tipo de causalidade, implica a necessidade de uma legislação própria que não a da necessidade natural, tendo em vista que, na concepção moral kantiana, o arbítrio humano não é necessitado, mas livre, quer dizer, a vontade não é determinada exclusivamente por móbeis e impulsos empíricos. Assim, a legislação que atua no caso de um arbítrio que não é necessitado por estímulos empíricos, só pode ser uma "lei" da liberdade. Ou seja, a liberdade nada mais é do que a propriedade ou modo de atuação deste tipo de causalidade humana, a saber, a vontade dos seres racionais.

Todavia, a mera capacidade de agir independentemente de estímulos empíricos é insuficiente para mostrar o caráter genuinamente moral da teoria prática de Kant. Segundo ele, a idéia da liberdade é "a chave para a explicação da autonomia da vontade" na medida em que o conceito negativo de liberdade está ligado ao conceito positivo da mesma enquanto capacidade autolegisladora ou autônoma, isto é, "a vontade é, em todas as ações, uma lei para si mesma” (GMS, Ak 447). Com efeito, o princípio da autonomia da vontade, ou seja, a capacidade humana de autodeterminação da vontade a partir de si mesma constitui a tese fundamental da concepção moral kantiana

\footnotetext{
${ }^{3} \mathrm{Na}$ literatura secundária, esta implicação mútua é denominada (por exemplo, por Allison) como a tese da reciprocidade.
} 
da GMS. Ora, como lemos na III Seção, esta afirmação representa a própria lei da moralidade entendida como um imperativo categórico, cuja explicitação remete às duas primeiras Seções em que há a exposição deste princípio.

Parece-nos, por um lado, que o que pode ser afirmado até este momento da argumentação é a implicação mútua, ou a reciprocidade entre as idéias da moralidade e da liberdade, mas de modo que, com isso, não há ainda nenhuma evidência quanto à estratégia de prova que será empreendida por Kant para justificar a realidade e a necessidade prática da lei moral concebida como autonomia da vontade. Isso implica, por outro lado, que o conceito de vontade aqui ainda não se refere ao modo exclusivamente humano de agir, mas à vontade de um ser puramente racional; numa palavra, os conceitos morais são tematizados neste contexto em um nível puro e a priori.

Logo, mesmo que o princípio da moralidade seja obtido por análise da idéia da liberdade, é preciso mostrar como o caráter analítico da lei moral para um ser puramente racional pode expressar uma "relação" sintética a priori para o ser racional humano. Dito em outros termos, a partir deste argumento da III Seção nós podemos pensar que a lei moral se manifesta como uma verdade analítica para a vontade de um ser puramente racional. Contudo, o problema consiste em mostrar como esta verdade analítica para um ser puramente racional pode obrigar moralmente o ser racional humano.

Por um lado, sabe-se que desta implicação mútua entre os conceitos de moralidade e de liberdade não é possível resolver este problema da prova da necessidade e da realidade prática do princípio moral, "pois liberdade e própria legislação da vontade são ambas autonomia, portanto conceitos transmutáveis, um dos quais porém não pode, por isso mesmo, ser usado para explicar o outro e fornecer o seu fundamento" (GMS, Ak 450).

Assim, por outro lado, a chave para a solução, consiste em investigar "se, quando nós nos pensamos, pela liberdade, como causas eficientes a priori, não adotamos um outro ponto de vista do que quando nos representamos a nós mesmos, segundo as nossas ações como efeitos que vemos diante dos nossos olhos" (GMS, Ak 450). Em outras palavras, o problema, segundo Kant, consiste em encontrar um terceiro termo independente da relação recíproca entre a idéia da lei e da liberdade que seja capaz de conectar a priori o teor deste princípio moral com a vontade humana. O resultado desta hipótese teórica ou desta construção abstrativa 
que o sujeito faz ao representar a si mesmo como um ser puramente racional e como um ser racional humano é o de que, assim,

(...) vemos que, quando nos pensamos livres, nos transpomos para o mundo inteligível como seus membros e reconhecemos a autonomia da vontade juntamente com a sua conseqüência - a moralidade, mas quando nos pensamos como obrigados, consideramo-nos como pertencentes ao mundo sensível e contudo ao mesmo tempo também do mundo inteligível (GMS, Ak 453).

A partir disso, fica claro que a justificação do princípio moral como obrigatório e necessário tem como base o conceito de liberdade. De fato, a tese de que a consciência da obrigação moral ou do dever depende da pressuposição da idéia da liberdade é explícita na III Seção da GMS de modo que podemos citar várias passagens em que é afirmado não só a implicação mútua entre esta idéia e o conceito de moralidade, como também à primazia epistemológica desta idéia em relação à consciência da lei moral. Assim, Kant diz, por exemplo:

(...) e assim são possíveis os imperativos categóricos, porque a idéia da liberdade faz de mim um membro do mundo inteligível; pelo que, se eu fosse só isto, todas as minhas ações seriam sempre conformes à autonomia da vontade; mas como ao mesmo tempo me vejo como membro do mundo sensível, essas minhas ações devem ser conformes a essa autonomia (GMS, Ak 454).

A partir desta passagem, podemos dizer que a representação da lei moral enquanto um imperativo categórico só é possível na medida em que a idéia da liberdade faz com que o ser racional humano represente a si mesmo como um ser puramente racional, reconhecendo, assim, a sua capacidade autônoma ou autolegisladora. Mas como o homem não é um ser puramente racional, mas também sensível, ou seja, que sofre a influência de estímulos e impulsos empíricos, a consciência desta autolegislação moral se manifesta como um mandamento ou uma obrigação moral.

No parágrafo seguinte a esta passagem citada acima, Kant afirma que "o uso prático da razão comum confirma a exatidão desta dedução" (GMS, Ak 454). Logo, se nós lemos esta passagem juntamente com a resposta 
kantiana exposta na $K p V$, então podemos dizer que na $G M S$ a idéia da liberdade consiste tanto na ratio essendi como na ratio cognoscendi da lei da moralidade tendo em vista que neste contexto é a idéia da liberdade que possibilita, ou seja, torna possível a representação do princípio moral enquanto obrigatório praticamente.

Vale chamar a atenção para o fato de que, na passagem supracitada, a argumentação não é puramente a priori na medida em que Kant fala aqui do imperativo categórico, logo se trata da representação da lei moral por um ser não puramente racional, mas também sensível. É verdade que o homem é capaz de representar a lei moral enquanto uma proposição analítica, tal como foi mostrado acima, na medida em que ele abstrai de sua sensibilidade. Todavia, o ser racional humano deve ser capaz de representar o imperativo categórico enquanto uma proposição sintética a priori e não apenas como uma proposição analítica.

Portanto, este argumento não pode ser identificado com aquele exposto na primeira parte da III Seção da GMS, pois, neste caso, Kant afirma que a consciência da obrigação ou do caráter coercitivo da lei moral depende da pressuposição da idéia da liberdade na medida em que esta idéia possibilita a representação do ser racional como um ser puramente racional. Ou seja, este segundo passo do argumento implica a dupla perspectiva que o ser racional humano pode representar a si mesmo, a saber, como um ser puramente racional e, ao mesmo tempo, como um ser racional humano. $\mathrm{Na}$ medida em que o homem representa a si mesmo deste duplo ponto de vista, ele reconhece que o princípio moral constitui uma obrigação, pois a sua vontade não é determinada sempre e somente por motivos racionais, mas também sensíveis. Ora, segundo Kant, este segundo novo argumento também pressupõe a idéia da liberdade pelo fato de que é através dela que o homem é capaz de representar a si mesmo desta dupla perspectiva. Em uma palavra, o princípio moral é considerado, aqui, como uma proposição não somente analítica, mas sintética a priori, sendo que a idéia da liberdade transcendental é condição de possibilidade do reconhecimento da obrigação moral; pois, como afirma Kant:

Da pressuposição desta idéia decorreu porém também a consciência de uma lei de ação que diz que os princípios subjetivos, isto é, as máximas, têm que ser sempre tomados de modo a valerem também objetivamente (GMS, Ak 449). 
E, num outro trecho:

O dever moral é, pois, um próprio querer necessário seu como membro de um mundo inteligível, e só é pensado por ele como dever na medida em que ele se considera ao mesmo tempo como membro do mundo sensível (GMS, Ak 455).

Com isso, fica claro que e porque o argumento da III Seção da GMS consiste em um argumento teórico-especulativo, a saber, porque a garantia da consciência da realidade e da necessidade prática do princípio moral depende da idéia transcendental da liberdade tendo em vista que esta remete ao terceiro termo independente necessário para a justificação do caráter obrigatório da lei moral. Ou seja, parece-nos que esta prova do reconhecimento da necessidade prática da lei moral não está baseada em uma idéia da própria razão prática pura, mas da razão teórico-especulativa, pois na $\mathrm{Kr} V$ ficou suficientemente claro que esta idéia pode ser apenas pensada pelo fato de que ela não contradiz as leis da natureza. Assim, se a justificativa de porque, afinal, o sujeito deve se submeter ao imperativo categórico depende da pressuposição da idéia da liberdade, então, no âmbito de investigação da $G M S$, a consciência da necessidade prática do princípio moral não se baseia em um argumento prático, mas teórico-especulativo, o qual consiste na representação da espontaneidade do sujeito concebido como um ser puramente racional. Com efeito, segundo a teoria moral kantiana de 1785, "a pretensão legítima que mesmo a razão humana vulgar tem à liberdade da vontade funda-se na consciência e na pressuposição admitida da independência da razão quanto a causas determinantes puramente subjetivas"4 (GMS, Ak 457).

Em resumo, na medida em que o homem se representa a si mesmo como um ser puramente racional a partir da idéia da liberdade transcendental, ele é capaz de reconhecer o princípio da moralidade enquanto um princípio autolegislador ou autônomo. Mas como o homem não é um ser puramente racional, mas também sensível, este princípio deve determinar o seu agir necessariamente. Sem entrar na questão se o argumento da III Seção da GMS é (ou não é circular), o ponto é que a consciência moral

\footnotetext{
${ }^{4}$ Esta passagem mostra claramente que a liberdade da vontade depende da consciência da liberdade em sentido transcendental.
} 
é derivada da liberdade transcendental. Kant apresenta ainda um outro argumento baseado na idéia da liberdade entendida como espontaneidade da faculdade de julgar, pois segundo ele:

(...) é impossível pensar uma razão que com a sua própria consciência recebesse de qualquer outra parte uma direção a respeito dos seus juízos, pois que então o sujeito atribuiria a determinação da faculdade de julgar, não à sua razão, mas a um impulso. Ela tem de considerar-se a si mesma como autora dos seus princípios, independente de influências estranhas; por conseguinte, como razão prática ou como vontade de um ser racional, tem de considerar-se a si mesma como livre; isto é, a vontade desse ser só pode ser uma vontade própria sob a idéia da liberdade, e, portanto, é preciso atribuir, em sentido prático, uma tal vontade a todos os seres racionais (GMS, Ak 448).

O problema deste argumento consiste em que a partir do reconhecimento da liberdade enquanto faculdade espontânea de julgar, não se segue a liberdade da faculdade de agir, pois a vontade, neste caso, deve ser determinada a agir com base em um princípio a priori e totalmente independente de princípios empíricos de determinação. Em outros termos, a partir da consciência da liberdade que o sujeito tem de que os seus juízos não são determinados por princípios heterônomos não se segue a consciência da liberdade considerada como a capacidade de determinação da vontade pelo princípio da autonomia da vontade; ou ainda, a liberdade prática não pode ser deduzida da liberdade transcendental. Numa palavra, da liberdade entendida enquanto faculdade espontânea do juízo não se pode deduzir a liberdade concebida como faculdade prática determinante da vontade humana ${ }^{5}$.

A partir destes argumentos baseados na idéia da liberdade transcendental, os quais pretendem mostrar como é possível um imperativo

\footnotetext{
${ }^{5}$ Tanto Henrich, como Guido de Almeida reconstroem este argumento e afirmam que ele consiste em uma tentativa de justificar a validade objetiva, isto é, necessária e universal, do princípio moral para a vontade de todo ser racional. Todavia, como foi afirmado acima, este argumento que pretende mostrar que a vontade é livre em sentido prático está baseado na consciência que o sujeito tem da sua capacidade espontânea no ato de julgar.
} 
categórico, Kant conclui a sua argumentação afirmando que esta pergunta acerca de tais imperativos

(...) pode, sem dúvida, responder-se na medida em que se pode indicar o único pressuposto de que depende a sua possibilidade, quer dizer, a idéia da liberdade (...), o que para o uso prático da razão, isto é, para a convicção da validade deste imperativo, e portanto também da lei moral é suficiente, mas como seja possível esse pressuposto mesmo, isso é o que nunca se deixará jamais aperceber por nenhuma razão humana (GMS, Ak 461).

Dito em outros termos, o sujeito necessita pressupor a idéia da liberdade para estar convicto da validade do imperativo categórico. Com base nesta reconstrução dos argumentos da III Seção da GMS, podemos afirmar que para a convicção ou a consciência prática do princípio moral é necessária a pressuposição da idéia da liberdade, ou seja, esta idéia é condição de possibilidade da consciência da necessidade prática ou da obrigatoriedade do princípio moral.

Contudo, parece-nos que com esta prova o problema que deve ser resolvido não encontra a sua solução, a saber, de encontrar uma figura que conecte o teor a priori da lei moral com a vontade humana. É importante observar, então, que esta questão só pode ser resolvida se há uma mudança na estratégia de prova da realidade e da necessidade prática do princípio moral; o que implica, então, uma nova resposta à pergunta: "donde provém que a lei moral obrigue” (GMS, Ak 450). Por conseguinte, tal resposta não pode estar fundamentada no uso teórico-especulativo da razão.

De fato, apesar de que a razão especulativa encontra-se sistematicamente no limite, e, portanto, só esta tem uma visão privilegiada do cognoscível e do incognoscível, ela é incapaz de determinar positivamente este espaço vazio ou estas idéias puras. Assim, ela "vê" este espaço vazio e, por isso, Kant afirma que a razão especulativa é capaz de transpor-se para este terreno das formas puras pela idéia da liberdade. Ou seja, quando ele afirma que o homem é capaz de representar a si mesmo porque é um ser racional, ele está querendo chamar a atenção apenas para esta capacidade espontânea do sujeito. Mas isso significa só que a razão especulativa não se opõe ao interesse e às necessidades do seu uso prático na medida em que se trata de uma só razão, que na sua aplicação deve se diferenciar. Logo, a razão 
especulativa é incapaz de determinar a realidade e a necessidade de se submeter a esta liberdade ${ }^{6}$.

Parece-nos que a mudança da estratégia e da natureza do argumento exposto na solução da $K p V$ é uma conseqüência do reconhecimento kantiano de que o sujeito só representa a si mesmo como livre porque a consciência a priori da obrigação moral faz com que ele reconheça também a sua liberdade (ou capacidade de agir independentemente de impulsos sensíveis e, ademais, por uma faculdade autônoma); argumento este apresentado na resposta definitiva da $K p V$.

Sendo assim, o ganho da $G M S^{7}$ parece ser, de fato, o de ter explicitado ou esclarecido o princípio sob o qual nós devemos julgar e agir moralmente. Com efeito, embora nós encontremos uma explicitação de qual é e como deve funcionar o princípio moral enquanto um princípio autolegislador ou autônomo, Kant pretende dar uma resposta nova e final na $K p V$ para quem nos pergunte porque o homem deve julgar e agir com base em um princípio com validade universal, resposta essa que está de acordo com os resultados da primeira Crítica na medida em que a razão especulativa "salvou contra todas as objeções a admissibilidade da liberdade, considerada negativamente, como totalmente compatível com aquelas proposições fundamentais e limitações da razão teórica pura” ( $K p V$, A 73).

Kant se dá conta de que o supracitado problema, a saber, mostrar como o princípio objetivo da moralidade pode se transformar num princípio subjetivo, não pode ser resolvido com base em um argumento teóricoespeculativo, ou ainda, pela derivação da moralidade da liberdade na medida

\footnotetext{
${ }^{6}$ Isso fica claro a partir da III Antinomia, de textos pré-críticos, do Prefácio da segunda edição da KrV. Kant não poderia ter tentado na primeira edição da KrV dar uma justificação da realidade e da necessidade prática do princípio moral nos moldes da GMS porque na primeira Crítica parece-nos que não há ainda a formulação explícita da moralidade entendida enquanto autonomia da vontade. De fato, embora a idéia da liberdade transcendental compreenda um significado ou uma dimensão positiva, não há ali uma concepção explícita do seu sentido genuinamente prático-moral enquanto causalidade prática da razão pura, ou seja, da capacidade que o sujeito tem, mediante a sua vontade, de ser "movido" ou determinado pela razão prática pura. Isto parece ser verdade se nos detemos no Cânone, pois, neste Capítulo da KrV, a consciência da lei moral só se torna efetiva e constitui um móbil da vontade se 0 sujeito pressupor as idéias de Deus e da imortalidade da alma.

${ }^{7} \mathrm{Na}$ verdade, o ganho da GMS não se resume na mera análise do imperativo categórico, e sim na descoberta do princípio moral enquanto autonomia. Isso significa que a GMS consegue mostrar porque a lei moral é válida objetivamente para a vontade de todo ser racional em geral, de modo que, como 0 próprio Kant reconhece nos últimos parágrafos da III Seção da GMS, falta ainda mostrar se e como é possível para o ser racional humano compreender a realidade e a necessidade prática de se submeter a este princípio moral universalmente válido.
} 
em que esta idéia nos transporta involuntariamente para a representação de nós mesmos como membros de um mundo inteligível ${ }^{8}$, tal como é apresentado na III Seção da GMS. Com efeito, este problema só é solucionado com base em um argumento prático. Ora, esta é a "descoberta" ou o rompimento da $K p V$ com a Grundlegung na medida em que na primeira fica claro que a consciência da lei moral é um produto da razão pura prática. É exatamente nesta direção que ele admite que na GMS o seguinte:

(...) parece, pois, que na ideia da liberdade pressupusemos apenas propriamente a lei moral, isto é o próprio princípio da autonomia da vontade, sem podermos demonstrar por si mesma a sua realidade e necessidade objectiva; teríamos então, na verdade, ganhado algo de muito importante, por termos determinado pelo menos o princípio autêntico com mais exactidão do que costuma suceder; mas, pelo que respeita à sua validade e à necessidade prática de se submeter a ele, nada teríamos adiantado (GMS, Ak 449).

Sendo assim, se interpretamos que o argumento da GMS consegue provar a realidade e a necessidade prática ou da obrigatoriedade do princípio moral para o ser racional humano, então parece-nos que não há como negar a contradição com os resultados da primeira Crítica na medida em que a partir da idéia da liberdade não se pode determinar aquele espaço vazio deixado pelo uso teórico-especulativo da razão. Ou seja, se nós sustentamos que na GMS há uma prova da realidade e do caráter obrigatório da lei da moralidade para o homem, então parece ser necessário investigar como integrar nesta solução os seguintes resultados da $K r V: 1$ ) da III Antinomia que sustenta que a razão especulativa é totalmente insuficiente para determinar "o que deve ser"; 2) o de que a razão teórico-especulativa, a qual, apesar de se encontrar no limite, não tem o direito de ultrapassá-lo. Isto é, ao pretender determinar aquele espaço vazio, a razão especulativa ultrapassaria o seu próprio limite que ela mesma determinou criticamente para si; em uma palavra, levado a termo este argumento, a razão especulativa cairia numa contradição consigo mesma.

${ }^{8}$ GMS, Ak 455. 
Isso significa que o leitor tem, pelo menos, duas possibilidades de interpretação da III Seção da GMS, a saber: ou se defende que ali nós já encontramos uma fundamentação da realidade e da necessidade prática do princípio moral com base na razão prática pura, ou se sustenta que esta tarefa é feita com base na pressuposição da idéia da liberdade transcendental, ou seja, com base em um argumento teórico-especulativo?.

Sendo assim, é exatamente nesta perspectiva, a saber, de que a razão teórico-especulativa não consegue mostrar em que consiste a realidade e a necessidade prática do princípio moral, por um lado, e, ao mesmo tempo, da solução crítica da $K p V$ que devemos ler uma passagem do Prefácio desta última em que ele afirma que "a razão prática obtém agora por si mesma, e sem ter acertado um compromisso com a razão especulativa, realidade (...) da liberdade (embora como conceito prático, também só para o uso prático), portanto confirma mediante um factum o que lá meramente podia ser pensado" (KpV, A 9).

Esta "confirmação, sequer esperável antes e muito satisfatória, do modo de pensar conseqüente" ( $K p V$, A 9) mostra que há uma mudança não só na estratégia da argumentação, como na "natureza" do mesmo na $K p V$, na medida em que nesta a consciência da lei moral tem o primado epistemológico $^{10}$ sobre a liberdade transcendental, e, portanto, a única faculdade capaz de preencher ou determinar aquele espaço vazio é a razão pura prática. Pois só ela pode "saber" e determinar necessariamente o que deve ser feito, ou seja, só ela é capaz de determinar assertóricamente o que só era afirmado problematicamente.

Por isso é importante observar que, embora a liberdade transcendental seja a razão de ser da lei moral, o "nosso conhecimento do

\footnotetext{
9 Por que se insiste em afirmar que 0 argumento da III Seção da GMS, o qual se baseia no reconhecimento da capacidade livre do homem, é baseado no uso teórico-especulativo da razão? Exatamente porque, como nos lembra Kant ainda na III Secção da GMS: "como uma razão pura , sem outros móbiles, possa ser prática, isto é, como o simples princípio da validade universal de todas as máximas como leis (que seria certamente a forma de uma razão pura prática), sem matéria alguma (objecto) da vontade em que de antemão pudesse tomar-se qualquer interesse, possa por si mesma fornecer um móbil e produzir um interesse que pudesse chamar-se puramente moral; ou, por outras palavras, como uma razão pura possa ser prática - explicar isto, eis o de que toda a razão humana é absolutamente incapaz; e todo esforço e todo o trabalho que se empreguem para buscar a explicação disto serão perdidos" (GMS, Ak 461). Ou seja, esta é a resposta que não poderia ficar em aberto na GMS se ali já houvesse uma resposta com base na razão prática pura, pois este problema parece ser respondido na $\mathrm{KpV}$ com a doutrina do fato da razão e do sentimento de respeito.

10 Ou seja, a consciência da obrigação moral consiste na ratio cognoscendi da liberdade.
} 
incondicionalmente prático" "só pode começar pela lei moral” $(K p V, \mathrm{~A}$ 52/53). É exatamente neste sentido da primazia epistemológica da lei moral em relação à liberdade que devemos ler aquele advérbio "agora" do Prefácio da $K p V$ que sustenta, mais uma vez, a tese de que nesta obra há a descoberta de que é a razão prática a única que pode garantir a necessidade prática e a realidade da liberdade transcendental.

Assim, a confirmação desta idéia, a qual constitui na filosofia prática "o momento próprio das dificuldades que desde sempre envolveram a questão sobre a sua possibilidade” ( $K r V$, B 561), também deve ser vista como um ganho para a filosofia especulativa pois a razão prática "resolve" aquilo que para ela era um problema.

Com efeito, tendo em vista que a razão "encontra-se" em "trânsito" ( $K p V$, A $11 / 12)$, esta confirmação prática da razão pura não é "vista como obstáculo que porventura só deve servir para preencher lacunas do sistema crítico da razão especulativa, mas" é vista "como verdadeiro membro que torna observável a interconexão do sistema” (KpV, A 12). É importante chamar a atenção para estes trechos em que se trata da interconexão sistemática dos dois domínios da razão, tendo em vista que, a idéia da liberdade é, ao mesmo tempo, um problema para o uso teórico-especulativo da razão, mas também, e, sobretudo, o pressuposto mais elementar da filosofia crítica (pois sem ela, ressalta Kant, não há natureza, nem liberdade), a qual só é confirmada, isto é, provada a sua realidade pelo uso prático da mesma.

$\mathrm{O}$ resultado da $K p V$, que, à primeira vista, pode parecer um pouco modesto e insatisfatório, ou ainda até pré-crítico e dogmático, como muitos afirmam, se mostra como a única solução possível e crítica dentro do programa da filosofia transcendental, pois o limite entre a esfera do cognoscível e o incognoscível é respeitado, ou seja, a razão teóricoespeculativa não infringe ou ultrapassa o seu próprio limite. Além disso, embora nós jamais possamos explicar ${ }^{11}$, ou seja, saber teoricamente "donde provém que a lei moral obrigue”, isto não implica a impossibilidade de um outro modo de compreensão e de acesso às idéias morais; sendo que a consciência da lei moral, ao confirmar a realidade prática da liberdade, também possibilita, segundo Kant, "ver” a interconexão sistemática dos dois

${ }^{11}$ Isso porque a esfera da explicação é o do uso teórico da razão. Cf. GMS, Ak 458/ 459. 
domínios da razão, que, como sempre é importante lembrar, são uma e a mesma razão que só na sua aplicação devem ser diferenciadas ${ }^{12}$.

Com isso fica claro que nós podemos ver a continuidade da $G M S$ e da $K p V$ no sentido de que Kant mantém o resultado crítico-sistemático da $K r V$ acerca da impossibilidade de explicar a necessidade de se submeter ao imperativo categórico. Não obstante a impossibilidade de explicar e, portanto, de conhecer (pelo instrumentário teórico da razão) a realidade e a necessidade da consciência da lei moral, a segunda Crítica traz, mesmo assim, um argumento novo para resolver este problema.

É exatamente aqui que ele se dá conta de que este só pode ser "resolvido" não com base em um argumento teórico-especulativo ou ainda, pela derivação da moralidade da liberdade, tal como é apresentado na III Seção, mas somente, e esta é a "descoberta" ou o rompimento da $K p V$ com a $G M S$, a saber, que esta tarefa só pode ser respondida com base em um argumento prático.

Vale mencionar dois trechos que poderiam sugerir que Kant está defendendo já na GMS uma prova da realidade e da necessidade do imperativo categórico com base na razão prática. $\mathrm{Um}^{13}$ deles é afirmado que "a pretensão legítima que mesmo a razão humana vulgar tem à liberdade da vontade funda-se na consciência e na pressuposição admitida da independência da razão quanto a causas determinantes puramente subjetivas (...)” (GMS, Ak 457). Mesmo que Kant faça uso do conceito "consciência”, parece-nos que não esta não se refere à representação da necessidade prática do princípio moral, ou seja, a consciência da necessidade e da obrigatoriedade da lei moral, que é a posição final kantiana com respeito à fundamentação moral. De fato, esta consciência a que ele remete parece consistir, por um lado, na consciência empírica da liberdade do arbítrio, e, por outro lado, na pressuposição ou admissão da liberdade transcendental, logo, na consciência a priori que um ser puramente racional tem da capacidade de agir independentemente da influência das inclinações. Nas linhas que seguem a passagem em que Kant faz uso do termo consciência, fica claro que não se trata da consciência prática da liberdade, pois

\footnotetext{
12 Vale lembrar que do ponto de vista teórico da razão, a consciência ou o conhecimento prático da liberdade, mesmo com toda a força do argumento do único fato a priori da razão, permanece sempre, do ponto de vista sistemático da razão, "apenas" um pensamento.

${ }^{13}$ Em um seminário feito em Marburg (2008), o Prof. Stark chamava a atenção justamente para esta passagem.
} 
O homem que, desta maneira, se considera como inteligência, coloca-se assim numa outra ordem de coisas e numa relação com princípios determinantes de espécie totalmente diferente, quando se pensa como inteligência dotada de vontade e por conseguinte de causalidade, do que quando se percebe como um fenômeno no mundo sensível (GMS, Ak 457).

Fica claro, com isso, que embora Kant faça uso do termo consciência, esta se refere à capacidade do ser racional de representar a si mesmo como um ser puramente racional e livre, ou ainda, como independente das determinações empíricas. Em outras palavras, a razão que obriga o homem a representar a si mesmo como inteligência e, por conseguinte, possibilitandolhe ter a consciência da sua capacidade autolegisladora consiste na consciência dele da sua independência das determinações da sensibilidade.

Mas numa outra passagem, o termo "praticamente" parece sugerir uma argumentação com base na razão pura prática. E, de fato, esta passagem parece mais próxima da solução da $K p V$, pois, segundo Kant

Não é somente muito possível (como a filosofia especulativa pode mostrar) pressupor esta liberdade da vontade (...), mas é também necessário, sem outra condição, para um ser racional que tem consciência da sua causalidade pela razão, por conseguinte de uma vontade (distinta dos desejos), admiti-la praticamente, isto é, na idéia, como condição de todas as suas ações voluntárias (GMS, Ak 461).

Embora Kant faça referência a essa admissão prática, não é claro se se trata da consciência da obrigação moral e do reconhecimento a priori da autocoerção que o ser racional humano sente enquanto se reconhece como autônomo, ou da consciência da liberdade no sentido negativo. A primeira interpretação poderia sustentar que, como os conceitos de liberdade e moralidade são transmutáveis, Kant talvez pudesse estar já pensando na direção da $K p V$. Assim, se ele está se referindo à consciência da liberdade transcendental, podemos interpretar essa passagem como já anunciando a solução do fato da razão, somente se entendermos que mesmo a idéia da liberdade transcendental já contém uma dimensão prática-positiva. Todavia, Kant afirma que a partir da significação positiva da liberdade transcendental, a qual consiste na idéia da espontaneidade e da autolegislação, não se pode inferir qual é a lei que deve determinar as ações morais. 
Em primeiro lugar, é importante lembrar que há outras passagens da $G M S$, da $K r V$ e de outros textos que mostram a convicção kantiana de que mesmo a razão humana vulgar tem consciência de um princípio moral. Então, do fato de que estes dois trechos da III Seção da GMS parecem indicar a resposta final da $K p V$, isto é, parecem defender um argumento com base no uso prático da razão pura, precisamos integrar estes na solução deste escrito de 1785. Além disso, em segundo lugar, se nós quiséssemos sustentar que a realidade da liberdade já na GMS é baseada na razão prática pura, seria preciso dar conta, como já foi mencionado, da mudança da natureza do argumento da segunda Crítica em que a lei moral consiste na ratio cognoscendi da liberdade e não vice versa como é sustentado na GMS.

Não obstante a mudança da natureza do argumento destas duas obras, vale destacar que é só na GMS que encontramos uma exposição detalhada do princípio da moralidade entendido como princípio da autonomia da vontade; exposição esta que não há na $K r V$. A III Seção da $G M S$ tem, então, a importante tarefa de mostrar como se articulam os conceitos fundamentais da ética kantiana na medida em que é explicitado que e como o ser racional humano reconhece o princípio moral de uma dupla perspectiva. Mas isso não significa que ali nós encontramos uma tentativa de provar a realidade e a necessidade prática da lei da moralidade, pois Kant parece reconhecer no fim desta Seção que é impossível provar "donde provém que a lei moral obrigue" com base no uso teórico-especulativo da razão.

Mesmo com o esclarecimento deste princípio autolegislador, parecenos que nesta obra Kant não tinha total clareza de que somente a razão pura prática pode determinar a realidade e a necessidade do princípio moral. Esta perspectiva de leitura possibilita também compreender que e porque não há menção no Prefácio da $G M S$ ao projeto da redação da $K p V$, tendo em vista que ele parece ter visto só mais tarde que o projeto da "fundamentação" de um princípio moral universalmente válido ainda não havia sido completado.

\section{REFERÊNCIAS BIBLIOGRÁFICAS:}

ALMEIDA, G. A de. "Crítica, Dedução e Facto da Razão". In: Analítica, v. 4, $\mathrm{n}^{\circ} 1$, p. 57-84, 1999.

BECK, L. W. A Commentary on Kant's Critique of Practical Reason. Chicago \& London: Phoenix Books: The University of Chicago Press, 1960. 
HENRICH, D. "Der Begriff der sittlichen Einsicht und Kants Lehre vom Faktum der Vernunft”. In: Prauss, G. (org.): Kant. Zur Deutung seiner Theorie von Erkennen und Handeln. Köln: Kiepenheuer \& Witsch, p. 223254, 1973.

KANT, I. Kritik der praktischen Vernunft. Hrsg. Bernd Kraft und Dieter Schönecker. Hamburg: Meiner, 1999.

. Grundlegung zur Metaphysik der Sitten. Hrsg. Bernd Kraft und Dieter Schönecker. Hamburg: Meiner, 1999.

. Crítica da Razão Pura. Tradução de Valério Rohden e Udo Baldur Moosburger. São Paulo: Abril Cultural, 1991.

- Crítica da Razão Prática. Tradução de Valério Rohden. São Paulo: Martins Fontes, 2002.

Fundamentação da Metafísica dos Costumes. Tradução de Paulo Quintela. Lisboa: Edições 70, 2001. 